http://dx.doi.org/10.12795/PH.1990.v05.i01.26

\title{
«Eros y el pajarero: Bión, fr. XIII Gow»
}

E. A. Ramos Jurado

En muy pocos años los estudios en nuestro país sobre los bucólicos griegos han experimentado importantes aportaciones. Los justos lamentos de nuestros filólogos en los casos de Mosco y Bión ${ }^{1}$ se han visto compensados con meritorias traducciones ${ }^{2}$ y tesis doctorales ${ }^{3}$ que se unen a los apreciables estudios que en nuestro decenio se han realizado sobre la obra del poeta de Esmirna ${ }^{4}$.

Sabido es que el tema del amor es omnipresente en los bucólicos griegos y en concreto en Bión. Desde su Epitafio de Adonis a su Epitalamio de Aquiles y Deidamía, pasando por los fragmentos conservados ${ }^{5}$, el amor impregna su obra. Es un amor de tipo convencional el que recorre sus fragmentos, que no confundamos, en no pocos casos son pequeños poemas completos ${ }^{6}$, miniaturas helenísticas artificiosas, $\mu \varepsilon \lambda v^{\prime} \delta p l \alpha^{7}$ al decir del autor. En concreto vamos a centrar nuestros análisis en un fragmento de

${ }^{1}$ M. Brioso Sánchez, Bucólicos griegos, Madrid, 1986, p. 36 y n. 56.

${ }^{2}$ M. Brioso Sánchez, cf. n. 1; M. García Teijeiro-M² T. Molinos Tejada, Bucólicos griegos, Madrid, 1986.

${ }^{3} \mathrm{M}^{\mathrm{a}} \mathrm{T}$. Molinos Tejada, Los dorismos del Corpus Bucolicorum, Universidad de Salamanca, 1988; M. Valpuesta Bermúdez, Estudio sobre la obra literaria de Bión de Esmirna, Universidad de Sevilla, 1989.

${ }^{4}$ Fundamentalmente los trabajos de M. Fantuzzi (Bionis Smyrnaei Adonidis Epitaphium, testo crítico e commento, Liverpool, 1985; «Eros e Muse: Bione fr. 9 Gow», Materiali e discussioni per l'analisi dei testi classici 4, 1980, pp. 183-186 = Theokrit und die griechische Bukolik, Darmstadt, 1986, pp. 368-373; «Bionis Epitaphium: contesto culturale e tipologia testuale», Philologus 125, 1.981, pp. 95-108) y el Index Verborum In Moschum et Bionem a cargo de M. Campbell (Hildesheim, Zürich-New York, 1987).

${ }^{5} \mathrm{El}$ amor presente en los frs. III, IX-XIV, XVI.

${ }^{6}$ II, VIII-XIV.

${ }^{7}$ Fr. VIII 1. 
Bión, un poema completo, el XIII Gow ${ }^{8}$, conservado por Estobeo ${ }^{9}$, en hexámetros, con el típico barniz dorio. Nuestra versión del texto es la siguiente:

Un pajarero, que aún joven, en un frondoso bosque cazaba aves con liga, vió al huidizo Amor posado en la rama de un boj. Al verlo, contento porque el pájaro aparentaba ser grande,

5 disponiendo todas sus varetas una tras otra, se puso a acechar a Amor, que de un lado a otro brincaba.

El muchacho, irritado por no lograr su objetivo, arrojando finalmente las varetas, se dirigió a un viejo labrador

que le había enseñado tal arte, se lo contó

10 y le mostró a Amor ya posado. Pero el viejo, sonriendo, movió la cabeza y replicó al muchacho: «Abstente de esa pieza, no te acerques a ese pájaro. Huye lejos. Es mal bicho. Feliz serás en tanto no lo cojas, pero si llegas a hacerte hombre,

15 éste, que ahora te rehuye y anda dando brincos, de grado vendrá a posarse de pronto en tu cabeza».

Este pequeño poema, cuyos ecos resuenan desde Longo a Ronsard ${ }^{10}$, nos presenta, pues, a un joven pajarero que penetra en un lugar sagrado boscoso, un $\alpha 2 \lambda \sigma o \varsigma$, con la intención de cazar, y que, confundienco a Amor con un ave, intenta capturarlo sin éxito, por lo cual acude a su anciano maestro que valora su conducta y le aconseja.

Sin duda el poema que inmediatamente podemos evocar, entre otros, es el Amor fugitivo de Mosco, en el que Afrodita pregona la huida de su siervo Amor y ofrece una recompensa por su captura y una descripción del fugitivo ${ }^{11}$ : visible externa pero no internamente, «alado como un pájaro», que «vuela de uno a otro», con arcos y flechas «amargas», y que «se posa» en el corazón de hombres y mujeres, los cuales, si lo atrapan, han de tratarlo sin piedad y evitar su beso dañino.

Sin embargo la estructura de ambos poemas es distinta. Frente al largo parlamento de Afrodita en Mosco, tenemos el carácter dramático de la acción en Bión. Frente a Afrodita que describe por completo, externa e internamente, a Amor, el joven sólo describe externamente a Eros y el anciano internamente. En efecto, el $\kappa \hat{\omega} \rho \varsigma_{\zeta}$ va de la alegría al arrebato infantil, el anciano simple y sabiamente sonríe y mueve la cabeza. El muchacho se aventura prematuramente en el bosque sagrado donde mora Amor; el anciano, por el contrario, para quien la tensión amorosa ha pasado y ha aprendido con

${ }^{8}$ XIII Gow (= Gallavotti, Beckby), X Legrand (= Wilamowitz).

9 Anth. IV 20, 57, con el encabezamiento «de la obra bucólica de Bión de Esmima».

${ }^{10}$ D. Cameron Allen, «Three Poems on Eros», Comparative Literature 8, 1956, pp. 177-193 (=Theokrit und die griechische Bukolik, pp. 346-367).

${ }^{11}$ Este tema del amor fugitivo con sus variantes lo encontramos en autores como Meleagro, Asclepiades, Calímaco o Anacreónticas. 
la experiencia, el Amor es bien conocido y, por ello, se convierte en magister amoris del atolondrado muchacho ${ }^{12}$. Este sólo capta lo externo ( $\left.\phi \alpha i ́ v \varepsilon \tau o ~ v .4\right)$ y lo único que es capaz de comunicar a su maestro es que se trata de un "gran pájaro» ${ }^{13}$, algo externo, superficial; el anciano, por el contrario, no va a lo exterior sino a su ser, «es mal bicho» ${ }^{14}$.

Un eco, como decíamos, de éste poema encontramos en Longo ${ }^{15}$, pero también aquí el tratamiento es diferente. En el novelista el magister amoris es Filetas y el papel de discípulo es desempeñado por Dafnis y Cloe. Es el maestro quien ha tratado de capturar a Amor sin conseguirlo y quien con un discurso responde a las preguntas de los muchachos sobre qué es el amor, «si niño o pájaro y cuál su poderío» ${ }^{16}$ : es un dios, capaz de volar, de inmenso poder, contra el que no hay más remedio que el mismo amor. Las diferencias, pues, son obvias.

Ahora bien, a nuestro juicio, el autor estructura su poema a la manera de fábula. No nos debe extrañar. La época helenística es una época creadora en este ámbito ${ }^{17}$, en la que fábula y poesía persisten en no pocos casos vinculadas, y no nos referimos simplemente a las versificaciones, por ejemplo, en trímetros yámbicos y coliambos por los cínicos, sino a la tradición que va, por ejemplo, de Calímaco a Horacio.

En efecto, la estructura es ternaria, aunque sea éste un rasgo que la fábula comparte con otros géneros. Tenemos la típica situación, conflicto y solución. El carácter dramático de la acción con personajes típicos de la época helenística, el cazador y el labrador. La ausencia de localización temporal y el uso, en ocasiones, de imperfectos junto con la abundancia de participios. La secuencia sujeto inicial simple -determinación local-participio-verbo de percepción física con su objeto. La limitación del estilo directo a la intervención final. Fórmula de localización espacial y de «vió» en la primera parte desencadenadora de la acción y de «decir» antes del cierre final. Comienzo de este cierre con imperativo. Función de epimitio a cargo del estilo directo en boca del magister amoris.

El tema, por otra parte, no es ajeno a la fábula, como tampoco a Bión en cuyo Epitafio de Adonis asistimos a los lamentos de Afrodita y los Amores por la suerte del infortunado cazador hijo de Cíniras. En las colecciones de fábulas el tema del cazador aparece con frecuencia, ya se trate del cazador cazado ${ }^{18}$, del pajarero astuto ${ }^{19}$ o moralista ${ }^{20}$, aunque el objeto de caza no sea en las fábulas Eros. Sin embargo su figura, incesante cazador, se presta a la inversión del tópico, el cazador cazado. Ya un autor

${ }^{12}$ Cf. D. C. Allen, art. cit., n. 10.

${ }^{13} \mathrm{~V} .4$.

14 V. 13.

${ }^{15}$ II 3-7.

16 III 7.

${ }^{17}$ Cf. F. Rodríguez Adrados, Historia de la fábula greco-latina, Madrid, 1979-1987.

18 «El pajarero y la serpiente» (115 P.= $117 \mathrm{H} .=137 \mathrm{Ch}$.).

19 «El pajarero y la alondra» (193 P.= $207 \mathrm{H} .=283 \mathrm{Ch}$.).

20 «El pajarero y la cigüeña» $(194 \mathrm{P} .=208 \mathrm{H} .=284 \mathrm{Ch}$.). Posible fabulación del pasaje de Esquilo relativo a Anfiarao, que se había unido, siendo justo, a una mala causa (Cf. F. Rodríguez Adrados, op., cit., III, p. 209). «El pajarero y la perdiz» (265 P.= 205 H.= 285 Ch.; Sintipas 26 P.). 
anónimo de la Antología Palatina ${ }^{21}$ se felicitaba por haber apresado a Eros, por haberse vengado de él:

¡Aplaudid, oh muchachos! A Eros cazó Arcesilao

y con los rojos lazos de Cipris lo pasea.

El mismo Meleagro ${ }^{22}$ nos presenta a Eros prisionero, amenazado por su captor, quien lo deja finalmente libre por el peligro que entraña. Es, por tanto, una figura que se prestaba a sutiles juegos. Recordemos el tratamiento que se hace de Eros en el Banquete platónico, ya sea por parte de Aristófanes y su historia del andrógino, como por el mismo Sócrates ${ }^{24}$ cuando narra el nacimiento de Eros a partir de Poros y Penía.

Se dirá que no pocos de éstos rasgos son comunes a la fábula y a otros géneros conexos. Es cierto. Pero la coincidencia de todos ellos no nos parece casual. No es extraño, en fin, que en una época creadora en el ámbito de la fábula un poeta como Bión haya escogido para su poema un marco literariamente aceptado.

Además, es un hecho reconocido la contaminación de géneros en época helenística, en la que elementos de unos los hallamos en otros, bien en el plano de la lengua, de los motivos literarios o de los ritmos. Hay nuevos gustos que hay que satisfacer, y con este fin se revisan los géneros tradicionales, se diluyen sus límites y se aproximan unos a otros, en una tensión entre tradición e innovación ${ }^{25}$. Un autor helenístico como Bión, pues, no tenía inconveniente en enmarcar su poema a la manera de una fábula, género que en su época gozaba de gran predilección.

Este mismo fenómeno de contaminación de géneros lleva a Bión a tratar de cubrir las sedes métricas a imitación homérica. Con ello resulta que algo que se repele de entrada, como es la fábula y la épica, se aproximan ${ }^{26}$. Sabemos que la no aparición de la fábula en Homero es un olvido consciente ${ }^{27}$. Los autores épicos posteriores no han empleado tampoco la fábula salvo Hesíodo, una sola vez y excepcionalmente ${ }^{28}$. En efecto, en Bión tienden a ocupar las mismas posiciones que en Homero: ع́v ở

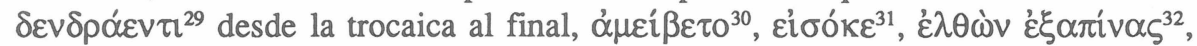

\section{${ }^{21}$ XII 112}

${ }^{22}$ A.P. V 179.

$23189 \mathrm{c}-191 \mathrm{~d}$.

${ }^{24} 203$ b-e. Del Banquete platónico deriva «Eros entre los hombres» (Cf. Himerio, Ecl. 10. 6= 444 P.).

${ }^{25}$ Cf. M. Brioso Sánchez, «Tradición e innovación en época helenística», Actas del VI Congreso Español de Estudios Clásicos, Madrid. 1983, pp. 127-146; «La Literatura Helenística», Historia de la Literatura griega, Madrid. 1988, pp. 781-794.

${ }^{26}$ Cf. M. Nøjgaard, La Fable Antique, Copenhague, 1964-1967, I, pp. 446-449.

${ }^{27}$ Las causas aducidas fluctúan entre el tono «grosero», no aristocrático y realista de la fábula en oposición a la epopeya (Crusius, Nøjgaard) y diferencias de estilo (Perry, Schmid-Stăhlin).

${ }^{28}$ Opera et Dies 202-212.

${ }^{29} \mathrm{~V}, 1=$ Od. IX 200, Hymni III 235, 384.

${ }^{30} \mathrm{~V}, 11, \sim$ s $\sim$ - Il. XXIV 200, 424; Od. VI 67, XV 434, 439.

${ }^{31}$ V. 14, 1 -11 . III 409, IX 46, XVI 455, VII 71; Hymni III 501.

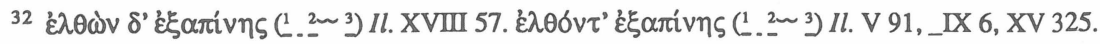




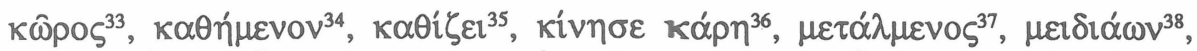

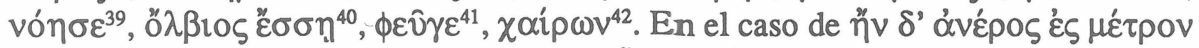

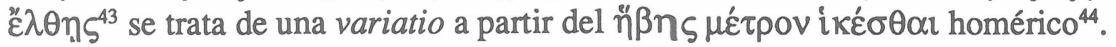

Como se ve la complejidad del poema, aparentemente simple, es enorme. Es una pequeña obra maestra donde cada elemento, de muy diversa procedencia, se unen en un todo armónico merced a la facultad creadora de una poeta bucólico, Bión de Esmirna.

${ }^{33}$ V. 1, ㄴ , pero sí kov̂por (Il. XV 284, VII 100, 328), kov̂por (Od. IX 154). De todas formas en Homero esta posición no es la usual.

${ }^{34}$ V. 10, $\stackrel{4}{4}=$ Od. V 151, XX 221, II 255, 369, III 186, IV 101,...

${ }^{35}$ V. 16, $\because 6$. En esta posición diferentes formas de $\kappa \alpha \theta i ́ \zeta \omega$ (Il. VIII 436, IX 484; Od. II 69, XVII 256, IX $103,179,471, \ldots .$.$) .$

${ }^{36}$ V. $11,{ }_{-3}^{3} \stackrel{4}{-}=$ Od. XVII $465,491, \mathrm{XX} 184$.

${ }^{37}$ V. 6, $\stackrel{4}{-}=I l$. V 336, XI 538, XII 305, XIII 362, XIV 443, XXIII 345.

${ }^{38}$ V. $11, \stackrel{1}{-} \underset{2}{-}=I l$. VIII 212, XXIII 786.

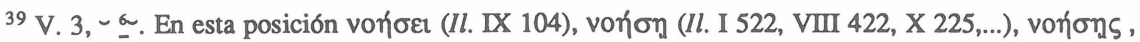
vónoov , ...

${ }^{40} \mathrm{~V}, 13,{ }_{-}^{5 \sim 6}{ }_{-}=I l$. XXIV 543, Od. XVIII 138, Hymni IV 379.

${ }^{41} \mathrm{~V} .13,1-1 \sim=I l . \mathrm{I} 173$. Muchas otras formas de $\phi \varepsilon v i \gamma \omega$ en esta posición, aunque no en imperativo.

${ }^{42}$ V. $4,{ }_{-}^{1}=I l$. XXIII 556, Od. VIII 200, XWII 251, 354.

${ }^{43}$ V. 14, , $-5 \sim 5$.

$444_{\text {_ 5 }} 6$ (Od. IV 668, XI 317, XVIII 217, XIX 532, Hymni II 166, 221). 
